\title{
Editorial Note: Data-Driven Multimedia Processing and Analysis
}

Published online: 2 August 2019

(C) Springer Science+Business Media, LLC, part of Springer Nature 2019

Multimedia Tools and Applications gratefully acknowledges the editorial work of the scholars listed below on the special issue entitled, "Data-Driven Multimedia Processing and Analysis."

Of 43 papers submitted to this issue, 23 were eventually accepted after a stringent peer-review process.

\section{Corresponding Guest Editor}

Dr. Huanqiang Zeng

Huaqiao University

China

zeng0043@hqu.edu.cn

\section{Guest Editors}

Dr. Junhui Hou

The City University of Hong Kong

Hong Kong

jh.hou@ cityu.edu.hk

\section{Dr. Lining Zhang}

University of Portsmouth

UK

lining.zhang@port.ac.uk

Publisher's note Springer Nature remains neutral with regard to jurisdictional claims in published maps and institutional affiliations. 